\title{
Genetic variants of glutamate receptor gene family in Taiwanese Kawasaki disease children with coronary artery aneurysms
}

\author{
Ying-Ju Lin 1,2, Jeng-Sheng Chang ${ }^{3}$, Xiang Liư ${ }^{4}$, Hsinyi Tsang ${ }^{4}$, Ting-Hsu Lin' ${ }^{1}$ Chiu-Chu Liao ${ }^{1}$, Shao-Mei Huang ${ }^{1}$, \\ Wen- Kuei Chien ${ }^{5,6}$, Jin-Hua Chen ${ }^{5,6}$, Jer-Yuarn Wu ${ }^{2,7}$, Chien-Hsiun Chen ${ }^{2,7}$, Li-Ching Chang ${ }^{7}$, Cheng-Wen Lin ${ }^{8}$, \\ Tsung-Jung $\mathrm{Ho}^{2,9,10}$ and Fuu-Jen Tsai ${ }^{1,2,11^{*}}$
}

\begin{abstract}
Background: Patients with Kawasaki disease (KD), a pediatric systemic vasculitis, may develop coronary artery aneurysm (CAA) as a complication. To investigate the role of glutamate receptors in KD and its CAA development, we performed genetic association studies.

Methods and results: We examined the whole family of glutamate receptors by genetic association studies in a Taiwanese cohort of $262 \mathrm{KD}$ patients. We identified glutamate receptor ionotropic, kainate 1 (GRIK1) as a novel susceptibility locus associated with CAA formation in KD. Statistically significant differences were noted for factors like fever duration, 1st Intravenous immunoglobulin (IVIG) used time (number of days after the first day of fever) and the GRIK1 (rs466013, rs425507, and rs38700) genetic variants. This significant association persisted even after using multivariate regression analysis (Full model: for rs466013: odds ratio $=2.12 ; 95 \% \mathrm{Cl}=1.22-3.65$; for rs425507: odds ratio $=2.16 ; 95 \% \mathrm{Cl}=1.26-3.76$; for rs388700: odds ratio $=2.16$; $95 \% \mathrm{Cl}=1.26-3.76$ ).

Conclusions: We demonstrated that GRIK1 polymorphisms are associated CAA formation in KD, even when adjusted for fever duration and IVIG used time, and may also serve as a genetic marker for the CAA formation in KD.
\end{abstract}

Keywords: KD, GRIK1, Single nucleotide polymorphism, CAA

\section{Background}

Patients with Kawasaki disease (KD), an acute systemic vasculitis, may develop coronary artery aneurysm (CAA) as a complication. KD is one of the leading causes of acquired cardiovascular diseases in childhood. Infectious agents, host immune dysregulation, and genetic susceptibility are thought to be responsible for the development of $\mathrm{KD}$ and its related complications [1-3]. However, the pathological mechanisms underlying $\mathrm{KD}$ remain to be elucidated.

Numerous genome-wide association studies have been conducted to identify host cellular genes that affect KD susceptibility [4-14] in the European, Japanese, Korean, and Taiwanese populations. In the European

\footnotetext{
* Correspondence: d0704@mail.cmuh.org.tw

'Department of Medical Research, China Medical University Hospital, Taichung, Taiwan

${ }^{2}$ School of Chinese Medicine, China Medical University, Taichung, Taiwan Full list of author information is available at the end of the article
}

population [11,13], no common SNPs have been identified as susceptibility loci for European KD. However, a common SNP (rs2233152; MIA gene) was observed in the European, Japanese, and Taiwanese populations [9-11]. Common gene SNPs among Asians including Japanese, Taiwanese, and Korean populations have also been observed $[4,6,9,10,12,14,15]$. Six SNPs, namely, rs2736340 $(B L K), \mathrm{rs} 2618479(B L K), \mathrm{rs} 6993775(B L K), \mathrm{rs} 10401344$ (ITPKC), rs2233152 (MIA), and rs4813003 (CD40) have been observed in both Japanese and Taiwanese populations $[9,10]$ (Additional files 1 and 2). These studies suggest that genes involved in the immune-regulatory responses and cardiovascular-related pathogenesis may contribute to KD susceptibility.

Glutamate receptors were initially demonstrated to play important roles in excitatory neurotransmission in the brain and interneuronal communication [16]. Based on their different activation mechanisms, glutamate receptors 
can be divided into 2 groups: ionotropic glutamate receptors (iGluRs) and metabotropic glutamate receptors (mGluRs). The human genome is known to contain at least 16 iGluRs and 8 mGluRs. Based on their agonist binding and electrophysiological properties, iGluRs can be classified to 3 groups: alpha-amino-3-hydroxy-5-methyl4-isoxazole (AMPA), N-methyl-D-aspartate (NMDA), and kainate (KA) receptors. Genetic mutations in glutamate receptors are associated with a number of human diseases including autism, Huntington's disease and Parkinson's disease $[17,18]$. In addition, glutamate receptors have been found to influence autoantigen/antibody interactions and multiple sclerosis. GluR3 (GRIA3) is known to act as an autoantigen in Rasmussen's encephalitis, suggesting a strong link between glutamate receptors and autoimmune interaction in certain degenerative diseases [19]. The regulation of glutamate receptor binding activity can reduce central nervous system (CNS) inflammation, apoptosis, and axonal damage [20]. In addition, glutamate receptors have also been implicated in cardiovascular diseases [21]. Glutamate receptor 1 (GluR1), an AMPA receptor subtype, can mediate the regulation of platelet activation through glutamate and GluR1 knockout mice develop in vivo thrombosis after a prolonged time [22]. The activation of GluR1 may contribute to the development of cardiovascular disease via accelerating thrombus formation.

Endothelial cells are principal targets for ischemic free-radical injury. Glutamate receptors are known to prevent nitric oxide-induced vascular injury [23]. On the other hand, activation of certain glutamate receptors was demonstrated to be a potential strategy for disrupting angiogenesis [24]. Coronary artery damage in KD is strongly associated with endothelial cell dysfunction [25]. Additional evidence suggests that glutamate receptors may influence KD pathogenesis [26,27].

To explore the role of glutamate receptors in KD development, we investigated the entire family of glutamate receptors by performing genetic association studies on a Taiwanese cohort of 262 KD patients. Our study identified glutamate receptor ionotropic, kainate 1 (GRIK1) as a novel susceptibility locus on 21q21.3. To our knowledge, this is the first instance to screen the glutamate receptor family for the association between genetic variants of glutamate receptors and CAA formation in KD.

\section{Results}

Genetic association study of the glutamate receptor gene family in Taiwanese KD children and controls

To identify KD susceptibility genes, a total of 53 SNPs of 16 genes within the glutamate receptor gene family including GRIK1, GRIK2, GRIK3, GRIK4, GRIK5, GRIA1, GRIA2, GRIA4, GRM1, GRM2, GRM3, GRM4, GRM5, GRM6, GRM7, and GRM8 genes were genotyped in 262
Taiwanese KD children and in 1107 healthy people from the general population of Taiwan who were Han Chinese ethnic background for the SNP association study (Table 1). No significant differences were found between these 2 groups, suggesting that the glutamate receptor family genes may not contribute to KD susceptibility.

\section{GRIK1 genetic polymorphisms may be related to KD-associated CAA complications}

To examine the role of glutamate receptors in KDassociated CAA complications, we analyzed the correlation between KD children and the whole glutamate gene family. As shown in Table 2, the genotype distributions (dominant model) of 6 glutamate gene SNPs were statistically different between these 2 groups $(p<0.05)$. These SNPs were rs466013, rs425507, rs388700, rs402280, rs17104835 and rs712723. Among these, 4 SNPs were found to be located in the GRIK1 gene ( $p=0.007,0.005$, 0.004 and 0.022 , respectively) (Additional file 1). GRIK1 consists of 18 exons and is located at $21 \mathrm{q} 21.3$ as shown in Figure 1. All SNPs were in Hardy-Weinberg equilibrium and had a successful genotyping frequency of $>99 \%$. The linkage disequilibrium (LD) structure of this region was also established, with 1 haplotype block determined. Four SNPs were located in that block. To evaluate the relationship among these 4 SNPs, pairwise LD analysis was performed. The D' statistics were all 1.0. Strong LD was observed in the following 2 groups of SNPs, group1 (rs466013, rs425507, rs388700), with the $r^{2}$ statistics $>0.5$ between every 2 SNPs in each group (data not shown). The frequencies of the TT and TC genotypes of GRIK1 (rs466013) were significantly higher in KD patients with CAA than those in patients without CAA (63.2\% for KD with CAA and $44.9 \%$ for KD without CAA complications; odds ratio $=2.11$ [95\% confidence interval $(\mathrm{CI})=1.22$ 3.65]). Similar results were also observed in rs425507, rs388700 and rs402280. These data suggest that GRIK1 may be a potential susceptibility locus involved in the development of KD with CAA complications.

\section{Multivariate regression analyses shows that GRIK1 genetic polymorphisms may be related to CAA formation in KD}

According to the above results, statistically significant differences in factors associated with CAA formation in KD were noted for the clinical characteristics including fever duration $(p<0.0001)$, first IVIG used time $(p<0.0001$; number of days after the first day of fever), and the GRIK1 (rs466013, rs425507, rs38700, and rs402280) genetic variants $(p=0.007, p=0.005, p=0.004$, and $p=0.022$, respectively) (Tables 1 and 3 ). To further confirm the genetic role of GRIK1, we used multivariate regression analyses to adjust those potential factors (i.e., fever duration and IVIG used time) that may affect the analysis. As shown in Table 3, significant associations between KD with CAA 
Table 1 Genotype distribution of glutamate receptor family gene SNPs in Taiwanese KD patients and controls

\begin{tabular}{|c|c|c|c|c|c|c|c|c|c|}
\hline \multirow[t]{2}{*}{ SNP } & \multirow[t]{2}{*}{ Chromosome } & \multirow[t]{2}{*}{ Cytoband } & \multirow{2}{*}{$\begin{array}{l}\text { Physical } \\
\text { position }\end{array}$} & \multirow{2}{*}{$\begin{array}{c}\text { Nearest } \\
\text { genes }\end{array}$} & & \multirow{2}{*}{$\begin{array}{l}\text { Controls } \\
\text { No. (\%) }\end{array}$} & \multicolumn{3}{|c|}{ KD patients } \\
\hline & & & & & & & No. (\%) & $p$ value & Odds ratio $(95 \% \mathrm{Cl})$ \\
\hline \multirow[t]{2}{*}{ rs466013 } & 21 & q21.3 & 29826390 & GRIK1 & $T+T C$ & $507(45.9)$ & $131(50.2)$ & 0.205 & $1.19(0.91-1.56)$ \\
\hline & & & & & CC & $599(54.1)$ & $130(49.8)$ & & 1 \\
\hline \multirow[t]{2}{*}{ rs425507 } & 21 & q21.3 & 29827658 & GRIKI & $G G+G A$ & $507(45.8)$ & $130(49.6)$ & 0.265 & $1.17(0.89-1.53)$ \\
\hline & & & & & AA & $600(54.2)$ & $132(50.4)$ & & 1 \\
\hline \multirow[t]{2}{*}{ rs388700 } & 21 & q21.3 & 29830158 & GRIK1 & $\pi+T A$ & $506(45.7)$ & $130(49.6)$ & 0.254 & $1.17(0.89-1.53)$ \\
\hline & & & & & AA & $601(54.3)$ & $132(50.4)$ & & 1 \\
\hline \multirow[t]{2}{*}{ rs402280 } & 21 & q21.3 & 29835401 & GRIK1 & $T+T A$ & $424(38.3)$ & $116(44.3)$ & 0.075 & $1.28(0.97-1.68)$ \\
\hline & & & & & AA & $683(61.7)$ & $146(55.7)$ & & 1 \\
\hline \multirow[t]{2}{*}{ rs17816480 } & 6 & q16.3 & 101522140 & GRIK2 & $\pi+T C$ & $201(18.2)$ & $48(18.3)$ & 0.951 & $1.01(0.71-1.43)$ \\
\hline & & & & & CC & $906(81.8)$ & $214(81.7)$ & & 1 \\
\hline \multirow[t]{2}{*}{ rs2786239 } & 6 & q16.3 & 101637565 & GRIK2 & $\mathrm{GG}+\mathrm{GA}$ & $186(16.8)$ & $45(17.2)$ & 0.885 & $1.03(0.72-1.47)$ \\
\hline & & & & & AA & $921(83.2)$ & $217(82.8)$ & & \\
\hline \multirow[t]{2}{*}{ rs4840194 } & 6 & q16.3 & 101768497 & GRIK2 & $\mathrm{CC}+\mathrm{CT}$ & $357(32.2)$ & 88 (33.6) & 0.677 & $1.06(0.80-1.41)$ \\
\hline & & & & & $\pi$ & $750(67.8)$ & $174(66.4)$ & & 1 \\
\hline \multirow[t]{2}{*}{ rs1310715 } & 6 & q16.3 & 101961427 & GRIK2 & $T+T C$ & $597(53)$ & $133(50.9)$ & 0.468 & $0.91(0.69-1.91)$ \\
\hline & & & & & CC & $520(47.0)$ & $128(49.1)$ & & 1 \\
\hline \multirow[t]{2}{*}{ rs527631 } & 1 & p34.3 & 36844396 & GRIK3 & $A A+A G$ & $172(15.5)$ & 45 (17.6) & 0.407 & $1.16(0.81-1.67)$ \\
\hline & & & & & GG & $935(84.5)$ & $210(82.4)$ & & 1 \\
\hline \multirow[t]{2}{*}{ rs476894 } & 1 & p34.3 & 36868682 & GRIK3 & $\mathrm{GG}+\mathrm{GA}$ & $234(21.1)$ & $63(24.0)$ & 0.305 & $1.18(0.86-1.62)$ \\
\hline & & & & & $\mathrm{AA}$ & 873 (78.9) & $199(76.0)$ & & 1 \\
\hline \multirow[t]{2}{*}{ rs541671 } & 1 & p34.3 & 36905238 & GRIK3 & $T+T A$ & $267(24.1)$ & 65 (25.9) & 0.554 & $1.10(0.80-1.51)$ \\
\hline & & & & & AA & $840(75.9)$ & $186(74.1)$ & & 1 \\
\hline \multirow[t]{2}{*}{ rs35317705 } & 1 & p34.3 & 36972969 & GRIK3 & $\mathrm{CC}+\mathrm{CT}$ & $128(11.6)$ & $33(12.6)$ & 0.641 & $1.10(0.73-1.66)$ \\
\hline & & & & & $\pi$ & $979(88.4)$ & $229(87.4)$ & & 1 \\
\hline \multirow[t]{2}{*}{ rs11218005 } & 11 & q23.3 & 120782227 & GRIK4 & $A A+A C$ & $132(11.9)$ & 35 (13.4) & 0.523 & $1.14(0.76-1.70)$ \\
\hline & & & & & CC & $975(88.1)$ & 227 (86.6) & & 1 \\
\hline \multirow[t]{2}{*}{ rs3901285 } & 11 & q23.3 & 120862726 & GRIK4 & $\pi+T C$ & $650(58.7)$ & $158(60.3)$ & 0.638 & $1.07(0.81-1.41)$ \\
\hline & & & & & $\mathrm{CC}$ & $457(41.3)$ & $104(39.7)$ & & 1 \\
\hline \multirow[t]{2}{*}{ rs4936566 } & 11 & q23.3 & 120944529 & GRIK4 & $A A+A G$ & $669(60.4)$ & $145(55.3)$ & 0.131 & $0.81(0.62-1.06)$ \\
\hline & & & & & GG & 438 (39.6) & $117(44.7)$ & & 1 \\
\hline rs443239 & 19 & $q 13.2$ & 42001892 & GRIK5 & $C C+C G$ & $289(26.1)$ & $64(24.4)$ & 0.576 & $0.91(0.67-1.25)$ \\
\hline & & & & & GG & 818 (73.9) & 198 (75.6) & & 1 \\
\hline rs1493395 & 5 & q33.2 & 153532297 & GRIA1 & $A A+A G$ & $565(51.1)$ & $125(47.7)$ & 0.326 & $0.87(0.67-1.14)$ \\
\hline & & & & & GG & $541(48.9)$ & $137(52.3)$ & & 1 \\
\hline rs12153489 & 5 & q33.2 & 153568777 & GRIA1 & $C C+C T$ & $1087(98.2)$ & 259 (98.9) & 0.454 & $1.59(0.47-5.39)$ \\
\hline & & & & & $\pi$ & $20(1.8)$ & $3(1.1)$ & & 1 \\
\hline rs4424038 & 5 & q33.2 & 153740704 & GRIA1 & $C C+C T$ & 1102 (99.5) & $262(100.0)$ & 0.276 & ND \\
\hline & & & & & $\pi$ & $5(0.5)$ & $0(0.0)$ & & 1 \\
\hline rs17035909 & 4 & q32.1 & 157247565 & GRIA2 & $\mathrm{AA}+\mathrm{AT}$ & $351(31.7)$ & 87 (33.3) & 0.640 & $1.07(0.80-1.43)$ \\
\hline & & & & & $\pi$ & $756(68.3)$ & $175(66.7)$ & & 1 \\
\hline rs17035959 & 4 & q32.1 & 157302204 & GRIA2 & $A A+A C$ & 1075 (97.1) & $255(97.3)$ & 0.848 & $1.08(0.47-2.48)$ \\
\hline & & & & & $\mathrm{CC}$ & $32(2.9)$ & $7(2.7)$ & & 1 \\
\hline
\end{tabular}


Table 1 Genotype distribution of glutamate receptor family gene SNPs in Taiwanese KD patients and controls (Continued)

\begin{tabular}{|c|c|c|c|c|c|c|c|c|c|}
\hline \multirow[t]{2}{*}{ rs7695870 } & 4 & q32.1 & 157342624 & GRIA2 & $C C+C T$ & $1082(97.7)$ & $258(98.5)$ & 0.460 & $1.49(0.51-4.32)$ \\
\hline & & & & & $\pi$ & $25(2.3)$ & $4(1.5)$ & & 1 \\
\hline \multirow[t]{2}{*}{ rs6855973 } & 4 & q32.1 & 157365463 & GRIA2 & $\mathrm{AA}+\mathrm{AT}$ & $1085(98)$ & $258(98.4)$ & 0.623 & $1.31(0.45-3.83)$ \\
\hline & & & & & $\pi$ & $22(2.0)$ & $4(1.6)$ & & 1 \\
\hline \multirow[t]{2}{*}{ rs10895875 } & 11 & $q 22.3$ & 105785485 & GRIA4 & $\mathrm{AA}+\mathrm{AT}$ & 715 (64.6) & $181(69.1)$ & 0.169 & $1.23(0.92-1.64)$ \\
\hline & & & & & $\pi$ & $392(35.4)$ & $81(30.9)$ & & 1 \\
\hline \multirow[t]{2}{*}{ rs4754136 } & 11 & $\mathrm{q} 22.3$ & 105846312 & GRIA4 & $\mathrm{CC}+\mathrm{CT}$ & 1102 (99.5) & 261 (99.6) & 0.877 & $1.18(0.14-10.18)$ \\
\hline & & & & & $\pi$ & $5(0.5)$ & $1(0.4)$ & & 1 \\
\hline \multirow[t]{2}{*}{ rs17104835 } & 11 & $\mathrm{q} 22.3$ & 105971356 & GRIA4 & $\mathrm{CC}+\mathrm{CT}$ & $447(40.4)$ & $104(39.8)$ & 0.839 & $0.97(0.74-1.28)$ \\
\hline & & & & & $\pi$ & $660(59.6)$ & $158(60.2)$ & & 1 \\
\hline \multirow[t]{2}{*}{ rs7750018 } & 6 & $\mathrm{q} 24.3$ & 146206595 & GRM1 & $\mathrm{CC}+\mathrm{CT}$ & $285(25.7)$ & $62(23.7)$ & 0.486 & $0.89(0.65-1.23)$ \\
\hline & & & & & $\pi$ & $822(74.3)$ & $200(76.3)$ & & 1 \\
\hline \multirow[t]{2}{*}{ rs362851 } & 6 & q24.3 & 146389448 & GRM1 & $C C+C G$ & $713(64.4)$ & $169(64.5)$ & 0.977 & $1.00(0.76-1.33)$ \\
\hline & & & & & GG & 394 (35.6) & $93(35.5)$ & & 1 \\
\hline \multirow[t]{2}{*}{ rs2300631 } & 6 & $\mathrm{q} 24.3$ & 146428918 & GRM1 & $A A+A G$ & $828(74.8)$ & $192(63.3)$ & 0.613 & $0.92(0.68-1.25)$ \\
\hline & & & & & GG & $279(25.2)$ & $70(26.7)$ & & 1 \\
\hline \multirow[t]{2}{*}{ rs12023603 } & 3 & p21.2 & 51466999 & GRM2 & $A A+A G$ & $1076(97.2)$ & 253 (96.6) & 0.583 & $0.81(0.38-1.72)$ \\
\hline & & & & & GG & $31(2.8)$ & $9(3.4)$ & & 1 \\
\hline \multirow[t]{2}{*}{ rs1983842 } & 3 & p21.2 & 51535259 & GRM2 & $A A+A G$ & 1070 (96.7) & 253 (96.6) & 0.940 & $0.97(0.46-2.04)$ \\
\hline & & & & & GG & $37(3.3)$ & $9(3.4)$ & & 1 \\
\hline \multirow[t]{2}{*}{ rs802441 } & 7 & $\mathrm{q} 21.11$ & 86657787 & GRM3 & $\mathrm{CC}+\mathrm{CT}$ & 1081 (97.6) & $255(97.3)$ & 0.759 & $0.88(0.38-2.04)$ \\
\hline & & & & & $\pi$ & $26(2.4)$ & $7(2.7)$ & & 1 \\
\hline \multirow[t]{2}{*}{ rs802466 } & 7 & $\mathrm{q} 21.11$ & 86698122 & GRM3 & $C C+C T$ & $222(20.0)$ & $44(16.8)$ & 0.230 & $0.80(0.56-1.15)$ \\
\hline & & & & & $\pi$ & $885(80.0)$ & $218(83.2)$ & & \\
\hline \multirow[t]{2}{*}{ rs12704286 } & 7 & $\mathrm{q} 21.11$ & 86745625 & GRM3 & $A A+A G$ & 364 (32.9) & $91(34.8)$ & 0.567 & $1.09(0.82-1.44)$ \\
\hline & & & & & GG & $743(67.1)$ & $171(65.2)$ & & 1 \\
\hline \multirow[t]{2}{*}{ rs17697415 } & 7 & $\mathrm{q} 21.11$ & 86772500 & GRM3 & $A A+A G$ & $138(12.5)$ & $34(13.0)$ & 0.822 & $1.05(0.70-1.57)$ \\
\hline & & & & & GG & 969 (87.5) & $228(87.0)$ & & 1 \\
\hline \multirow[t]{2}{*}{ rs1873254 } & 6 & p21.31 & 34058712 & GRM4 & $A A+A G$ & $518(55.9)$ & $150(57.4)$ & 0.096 & $1.26(0.96-1.66)$ \\
\hline & & & & & GG & $488(44.1)$ & $112(42.6)$ & & 1 \\
\hline \multirow[t]{2}{*}{ rs937039 } & 6 & p21.31 & 34075875 & GRM4 & $A A+A G$ & 1090 (98.5) & $260(99.2)$ & 0.337 & $2.03(0.47-8.83)$ \\
\hline & & & & & GG & $17(1.5)$ & $2(0.8)$ & & 1 \\
\hline \multirow[t]{2}{*}{ rs1565361 } & 6 & p21.31 & 34089248 & GRM4 & $\mathrm{CC}+\mathrm{CT}$ & $503(45.5)$ & $117(44.7)$ & 0.819 & $0.97(0.74-1.27)$ \\
\hline & & & & & $\pi$ & $604(54.5)$ & $145(55.3)$ & & 1 \\
\hline \multirow[t]{2}{*}{ rs4106126 } & 11 & q14.2 & 88647181 & GRM5 & $\mathrm{CC}+\mathrm{CT}$ & 1093 (98.7) & $256(97.7)$ & 0.214 & $0.55(0.21-1.44)$ \\
\hline & & & & & $\pi$ & $14(1.3)$ & $6(2.3)$ & & 1 \\
\hline \multirow[t]{2}{*}{ rs1391878 } & 11 & q14.2 & 88713212 & GRM5 & $C C+C T$ & $264(23.9)$ & $58(22.1)$ & 0.557 & $0.91(0.66-1.25)$ \\
\hline & & & & & $\pi$ & $843(76.1)$ & $204(77.9)$ & & 1 \\
\hline \multirow[t]{2}{*}{ rs12787863 } & 11 & q14.2 & 88810547 & GRM5 & $A A+A G$ & $447(40.4)$ & $110(42.0)$ & 0.634 & $1.07(0.81-1.40)$ \\
\hline & & & & & GG & $660(59.6)$ & $152(58.0)$ & & 1 \\
\hline \multirow[t]{2}{*}{ rs7126679 } & 11 & q14.2 & 89020677 & GRM5 & $A A+A G$ & $651(58.9)$ & $160(61.1)$ & 0.513 & $1.10(0.83-1.44)$ \\
\hline & & & & & GG & $455(41.1)$ & $102(38.9)$ & & 1 \\
\hline \multirow[t]{2}{*}{ rs2856354 } & 5 & q35.3 & 178978728 & GRM6 & $A A+A G$ & 1055 (95.3) & $244(93.1)$ & 0.151 & $0.67(0.38-1.16)$ \\
\hline & & & & & GG & $52(4.7)$ & $18(6.9)$ & & 1 \\
\hline
\end{tabular}


Table 1 Genotype distribution of glutamate receptor family gene SNPs in Taiwanese KD patients and controls (Continued)

\begin{tabular}{|c|c|c|c|c|c|c|c|c|c|}
\hline \multirow[t]{2}{*}{ rs10464073 } & 5 & $\mathrm{q} 35.3$ & 178982284 & GRM6 & $\overline{A A+A G}$ & $1056(95.4)$ & $244(93.1)$ & 0.132 & $0.65(0.38-1.14)$ \\
\hline & & & & & GG & $51(4.6)$ & $18(6.9)$ & & 1 \\
\hline \multirow[t]{2}{*}{ rs17078880 } & 5 & q35.3 & 178983436 & GRM6 & $\mathrm{CC}+\mathrm{CT}$ & $1089(98.4)$ & $258(98.5)$ & 0.908 & $1.07(0.36-3.18)$ \\
\hline & & & & & $\pi$ & $18(1.6)$ & $4(1.5)$ & & 1 \\
\hline \multirow[t]{2}{*}{ rs2645341 } & 5 & q35.3 & 178984314 & GRM6 & $A A+A G$ & $1087(98.2)$ & $258(98.5)$ & 0.756 & $1.19(0.40-3.50)$ \\
\hline & & & & & GG & $20(1.8)$ & $4(1.5)$ & & 1 \\
\hline \multirow[t]{2}{*}{ rs6764411 } & 3 & p26.1 & 7101864 & GRM7 & $A A+A C$ & 927 (83.8) & $211(80.5)$ & 0.202 & $0.80(0.57-1.13)$ \\
\hline & & & & & CC & 179 (16.2) & $51(19.5)$ & & 1 \\
\hline \multirow[t]{2}{*}{ rs17697928 } & 3 & p26.1 & 7326084 & GRM7 & $A A+A G$ & 861 (77.7) & $199(80)$ & 0.525 & $0.90(0.66-1.24)$ \\
\hline & & & & & GG & $246(22.3)$ & $51(19.5)$ & & 1 \\
\hline \multirow[t]{2}{*}{ rs779741 } & 3 & p26.1 & 7541915 & GRM7 & $A A+A C$ & 917 (82.8) & $218(83.2)$ & 0.886 & $1.03(0.72-1.47)$ \\
\hline & & & & & CC & $190(17.2)$ & $44(16.8)$ & & 1 \\
\hline \multirow[t]{2}{*}{ rs1354405 } & 3 & p26.1 & 7690304 & GRM7 & $A A+A G$ & $1012(91.4)$ & $236(90.1)$ & 0.491 & $0.85(0.54-1.34)$ \\
\hline & & & & & GG & $95(8.6)$ & $26(9.9)$ & & 1 \\
\hline \multirow[t]{2}{*}{ rs712723 } & 7 & q31.33 & 126439090 & GRM8 & $C C+C T$ & 698 (63.0) & $174(66.4)$ & 0.309 & $1.16(0.87-1.54)$ \\
\hline & & & & & $\pi$ & 409 (37.0) & 88 (33.6) & & 1 \\
\hline \multirow[t]{2}{*}{ rs17627206 } & 7 & q31.33 & 126793483 & GRM8 & $A A+A G$ & $110(9.9)$ & $28(10.7)$ & 0.717 & $1.08(0.70-1.68)$ \\
\hline & & & & & GG & 997 (90.1) & 234 (89.3) & & 1 \\
\hline \multirow[t]{2}{*}{ rs11563505 } & 7 & q31.33 & 127059729 & GRM8 & $\mathrm{CC}+\mathrm{CT}$ & $1086(98.1)$ & $258(98.5)$ & 0.687 & $1.25(0.42-3.66)$ \\
\hline & & & & & $\pi$ & $21(1.9)$ & $4(1.5)$ & & 1 \\
\hline
\end{tabular}

GRIK, glutamate receptor, ionotropic, kainate; GRIA, glutamate receptor, ionotropic, AMPA; GRM, glutamate receptor, metabotropic, SNP, single nucleotide polymorphism; $\mathrm{Cl}$, confidence interval.

$p$-values were obtained by chi-square test ( $2 \times 2$ table).

Statistical significance was considered as $p$ value $<0.05$.

Physical position of individual SNPs was based on the NCBI Assembly database: GRCH38 version.

complications and the GRIK1 (rs466013, rs425507, rs38700 and rs402280) genetic variants were observed (Full model: for rs466013: odds ratio $=2.12 ; 95 \% \mathrm{CI}=$ 1.22-3.65; for rs425507: odds ratio $=2.16$; $95 \% \mathrm{CI}=1.26$ 3.76; for rs388700: odds ratio $=2.16$; $95 \% \mathrm{CI}=1.26-3.76$; for rs402280: odds ratio $=1.89 ; 95 \% \mathrm{CI}=1.09-3.21$ ). Taken together, these data suggest that the significant association observed between CAA complications and the presence of the GRIK1 genotypes persists even after adjusting for the potential factors.

\section{Discussion}

Previous research from our lab suggests that the NMDA receptor (GRIN3A) from the glutamate receptor family may influence KD pathogenesis [26]. In this study, we screened the entire glutamate receptor family including the iGluRs and mGluRs (GRIK, GRIA and GRM gene families) and identified another member, namely GRIK1, that may be involved in the development of KD-associated CAA complications in Taiwanese children of Han Chinese ethnic background. The most striking finding of this study is that 4 GRIK1 gene variants were found to be strongly associated with the presence of CAA in KD patients, even in the multivariable model.
Our genetic association study showed that none of the genes of the glutamate receptor gene family including GRIK1, GRIK2, GRIK3, GRIK4, GRIK5, GRIA1, GRIA2, GRIA4, GRM1, GRM2, GRM3, GRM4, GRM5, GRM6, $G R M 7$, and GRM8 genes contributed to KD susceptibility. However, genetic variation of the GRIK1 locus may potential induce susceptibility to the development of KD with CAA complications. The significant association observed between KD with CAA complications and the GRIK1 genetic variants (rs466013, rs425507, rs38700, and rs402280) was found to persist even after adjusting for fever duration and first IVIG used time. These results suggest that the GRIK1 gene may be involved in CAA formation of KD. GRIK1 polymorphisms have been investigation for their associations with different diseases including Juvenile absence epilepsy $[28,29]$, schizophrenia [30,31], alcohol dependence [32], topiramate's effects on heavy drinking [33,34], topiramate-induced side effects [35], and hepatitis B virus (HBV)-related hepatocellular carcinoma [36]. However, these GRIK1 polymorphism data of various studies are also not absolutely consistent and conclusive. These studies show that GRIK1 gene may mainly contribute to neuropsychological diseases. Glutamate is known to signal and is released by nerves, 
Table 2 Association of the genetic variants of glutamate receptor family genes in Taiwanese KD children according to the presence or absence of CAA

\begin{tabular}{|c|c|c|c|c|c|c|c|c|c|}
\hline \multirow[t]{2}{*}{ SNP } & \multirow[t]{2}{*}{ Chromosome } & \multirow[t]{2}{*}{ Cytoband } & \multirow{2}{*}{$\begin{array}{l}\text { Physical } \\
\text { position }\end{array}$} & \multirow{2}{*}{$\begin{array}{c}\text { Nearest } \\
\text { genes }\end{array}$} & \multicolumn{2}{|c|}{ KD CAA- } & \multicolumn{3}{|c|}{ KD CAA+ } \\
\hline & & & & & & No. (\%) & No. (\%) & $p$ value & Odds ratio $(95 \% \mathrm{Cl})$ \\
\hline \multirow[t]{2}{*}{ rs466013 } & 21 & q21.3 & 29826390 & GRIK1 & $\mathrm{TT}+\mathrm{TC}$ & $83(44.9)$ & $48(63.2)$ & 0.007 & $2.11(1.22-3.65)$ \\
\hline & & & & & CC & $102(55.1)$ & $28(36.8)$ & & 1 \\
\hline \multirow[t]{2}{*}{ rs425507 } & 21 & $q 21.3$ & 29827658 & GRIK1 & $\mathrm{G}+\mathrm{GA}$ & $82(44.1)$ & $48(63.2)$ & 0.01 & $2.17(1.26-3.76)$ \\
\hline & & & & & $\mathrm{AA}$ & $104(55.9)$ & $28(36.8)$ & & 1 \\
\hline \multirow[t]{2}{*}{ rs388700 } & 21 & q21.3 & 29830158 & GRIK1 & $\Pi+\mathrm{TA}$ & $81(44.1)$ & $48(63.2)$ & 0.004 & $2.20(1.27-3.81)$ \\
\hline & & & & & AA & $104(55.9)$ & $28(36.8)$ & & 1 \\
\hline \multirow[t]{2}{*}{ rs402280 } & 21 & q21.3 & 29835401 & GRIK1 & $\Pi+\mathrm{TA}$ & $74(39.8)$ & $42(55.2)$ & 0.022 & $1.87(1.09-3.21)$ \\
\hline & & & & & AA & $112(60.2)$ & $34(44.8)$ & & 1 \\
\hline \multirow[t]{2}{*}{ rs17816480 } & 6 & $q 16.3$ & 101522140 & GRIK2 & $\mathrm{TT}+\mathrm{TC}$ & $30(16.1)$ & $18(23.7)$ & 0.151 & $1.61(0.84-3.11)$ \\
\hline & & & & & $\mathrm{CC}$ & $156(83.9)$ & $58(76.3)$ & & 1 \\
\hline \multirow[t]{2}{*}{ rs2786239 } & 6 & q16.3 & 101637565 & GRIK2 & $\mathrm{GG}+\mathrm{GA}$ & 29 (15.6) & $16(21.1)$ & 0.288 & $1.44(0.73-2.85)$ \\
\hline & & & & & $\mathrm{AA}$ & $157(84.4)$ & $60(78.9)$ & & 1 \\
\hline \multirow[t]{2}{*}{ rs4840194 } & 6 & q16.3 & 101768497 & GRIK2 & $C C+C T$ & $64(34.4))$ & 24 (31.6) & 0.660 & $0.88(0.50-1.56)$ \\
\hline & & & & & $\pi$ & $122(65.6)$ & $52(68.4)$ & & 1 \\
\hline \multirow[t]{2}{*}{ rs1310715 } & 6 & q16.3 & 101961427 & GRIK2 & $T+\mathrm{TC}$ & $91(49.2)$ & $42(55.3)$ & 0.373 & $1.28(0.75-2.18)$ \\
\hline & & & & & CC & $94(50.8)$ & $34(44.7)$ & & 1 \\
\hline \multirow[t]{2}{*}{ rs527631 } & 1 & p34.3 & 36844396 & GRIK3 & $A A+A G$ & $32(17.6)$ & $13(17.8)$ & 0.966 & $1.02(0.50-2.07)$ \\
\hline & & & & & GG & $150(82.4)$ & $60(82.2)$ & & 1 \\
\hline \multirow[t]{2}{*}{ rs476894 } & 1 & p34.3 & 36868682 & GRIK3 & $\mathrm{GG}+\mathrm{GA}$ & $45(24.2)$ & $18(23.7)$ & 0.930 & $0.97(0.52-1.82)$ \\
\hline & & & & & $\mathrm{AA}$ & $141(75.8)$ & $58(76.3)$ & & 1 \\
\hline \multirow[t]{2}{*}{ rs541671 } & 1 & p34.3 & 36905238 & GRIK3 & $T+\mathrm{TA}$ & $47(26.1)$ & 18 (25.3) & 0.902 & $0.96(0.51-1.80)$ \\
\hline & & & & & AA & $133(73.9)$ & $53(74.7)$ & & 1 \\
\hline \multirow[t]{2}{*}{ rs35317705 } & 1 & p34.3 & 36972969 & GRIK3 & $\mathrm{CC}+\mathrm{CT}$ & $22(11.8)$ & $11(14.5)$ & 0.558 & $1.26(0.58-2.75)$ \\
\hline & & & & & $\pi$ & $164(88.2)$ & 65 (85.5) & & 1 \\
\hline \multirow[t]{2}{*}{ rs11218005 } & 11 & q23.3 & 120782227 & GRIK4 & $A A+A C$ & $27(14.5)$ & $8(10.5)$ & 0.389 & $0.69(0.30-1.60)$ \\
\hline & & & & & $\mathrm{CC}$ & $159(85.5)$ & $68(89.5)$ & & 1 \\
\hline \multirow[t]{2}{*}{ rs3901285 } & 11 & q23.3 & 120862726 & GRIK4 & $T+\mathrm{TC}$ & $113(60.7)$ & $45(59.2)$ & 0.817 & $0.94(0.54-1.62)$ \\
\hline & & & & & CC & $73(39.3)$ & $31(40.8)$ & & 1 \\
\hline \multirow[t]{2}{*}{ rs4936566 } & 11 & q23.3 & 120944529 & GRIK4 & $A A+A G$ & $104(55.9)$ & $41(54.0)$ & 0.771 & $0.92(0.54-1.58)$ \\
\hline & & & & & GG & $82(44.1)$ & $35(46.0)$ & & 1 \\
\hline rs443239 & 19 & $q 13.2$ & 42001892 & GRIK5 & $\mathrm{CC}+\mathrm{CG}$ & $45(24.2)$ & $19(25.0)$ & 0.890 & $1.04(0.56-1.94)$ \\
\hline & & & & & GG & $141(75.8)$ & $57(75.0)$ & & 1 \\
\hline rs1493395 & 5 & q33.2 & 153532297 & GRIA1 & $A A+A G$ & $88(47.3)$ & $37(48.7)$ & 0.840 & $1.06(0.62-1.80)$ \\
\hline & & & & & GG & $98(52.7)$ & 39 (51.3) & & 1 \\
\hline rs12153489 & 5 & q33.2 & 153568777 & GRIA1 & $\Pi+C T$ & $40(21.5)$ & $19(25.0)$ & 0.539 & $1.22(0.65-2.28)$ \\
\hline & & & & & CC & 146 (78.5) & $57(75.0)$ & & 1 \\
\hline rs4424038 & 5 & q33.2 & 153740704 & GRIA1 & $\Pi+C T$ & $23(12.4)$ & $10(13.2)$ & 0.861 & $1.07(0.48-2.38)$ \\
\hline & & & & & CC & 163 (87.6) & 66 (86.8) & & 1 \\
\hline rs17035909 & 4 & q32.1 & 157247565 & GRIA2 & $A A+A T$ & $66(35.7)$ & 21 (27.6) & 0.210 & $0.69(0.38-1.24)$ \\
\hline & & & & & $\pi$ & 119 (64.3) & $55(72.4)$ & & 1 \\
\hline rs17035959 & 4 & q32.1 & 157302204 & GRIA2 & $C C+A C$ & $72(38.7)$ & 25 (32.9) & 0.376 & $0.78(0.44-1.36)$ \\
\hline & & & & & AA & $114(61.3)$ & $51(67.1)$ & & 1 \\
\hline
\end{tabular}


Table 2 Association of the genetic variants of glutamate receptor family genes in Taiwanese KD children according to the presence or absence of CAA (Continued)

\begin{tabular}{|c|c|c|c|c|c|c|c|c|c|}
\hline \multirow[t]{2}{*}{ rs7695870 } & 4 & q32.1 & 157342624 & GRIA2 & $\pi+C T$ & $50(26.9)$ & $26(34.2)$ & 0.236 & $1.41(0.80-2.51)$ \\
\hline & & & & & $\mathrm{CC}$ & $136(73.1)$ & $50(65.8)$ & & 1 \\
\hline \multirow[t]{2}{*}{ rs6855973 } & 4 & q32.1 & 157365463 & GRIA2 & $\pi+A T$ & $60(33.2)$ & $18(24.0)$ & 0.148 & $0.64(0.34-1.18)$ \\
\hline & & & & & AA & $121(66.8)$ & $57(76.0)$ & & 1 \\
\hline \multirow[t]{2}{*}{ rs10895875 } & 11 & q22.3 & 105785485 & GRIA4 & $A A+A T$ & $130(69.9)$ & $51(67.1)$ & 0.673 & $1.16(0.58-2.30)$ \\
\hline & & & & & $\pi$ & $56(30.1)$ & $25(32.9)$ & & 1 \\
\hline \multirow[t]{2}{*}{ rs4754136 } & 11 & q22.3 & 105846312 & GRIA4 & $\pi+C T$ & $26(14.0)$ & $5(6.6)$ & 0.092 & $0.43(0.16-1.17)$ \\
\hline & & & & & $\mathrm{CC}$ & $160(86.0)$ & $71(93.4)$ & & 1 \\
\hline \multirow[t]{2}{*}{ rs17104835 } & 11 & q22.3 & 105971356 & GRIA4 & $\mathrm{CC}+\mathrm{CT}$ & $66(35.7)$ & $38(50)$ & 0.032 & $1.80(1.05-3.10)$ \\
\hline & & & & & $\pi$ & $119(64.3)$ & $38(50)$ & & 1 \\
\hline \multirow[t]{2}{*}{ rs7750018 } & 6 & q24.3 & 146206595 & GRM1 & $\mathrm{CC}+\mathrm{CT}$ & $43(23.1)$ & $19(25.0)$ & 0.745 & $1.11(0.60-2.06)$ \\
\hline & & & & & $\pi$ & $143(76.9)$ & $57(75.0)$ & & 1 \\
\hline \multirow[t]{2}{*}{ rs362851 } & 6 & q24.3 & 146389448 & GRM1 & $C C+C G$ & $117(62.9)$ & $52(68.4)$ & 0.397 & $1.28(0.72-2.25)$ \\
\hline & & & & & GG & $69(37.1)$ & 24 (31.6) & & 1 \\
\hline \multirow[t]{2}{*}{ rs2300631 } & 6 & q24.3 & 146428918 & GRM1 & $A A+A G$ & $135(72.7)$ & $57(75.0)$ & 0.688 & $1.13(0.62-2.09)$ \\
\hline & & & & & GG & $51(27.4)$ & $19(25.0)$ & & 1 \\
\hline \multirow[t]{2}{*}{ rs12023603 } & 1 & p21.2 & 51466999 & GRM2 & $\mathrm{GG}+\mathrm{AG}$ & $50(26.9)$ & $22(28.9)$ & 0.734 & $1.11(0.61-2.00)$ \\
\hline & & & & & AA & $136(73.1)$ & $54(71.1)$ & & 1 \\
\hline \multirow[t]{2}{*}{ rs1983842 } & 1 & p21.2 & 51535259 & GRM2 & $\mathrm{GG}+\mathrm{AG}$ & $56(30.1))$ & $23(30.2)$ & 0.980 & $1.01(0.56-1.80)$ \\
\hline & & & & & AA & $130(69.9)$ & $53(69.8)$ & & 1 \\
\hline \multirow[t]{2}{*}{ rs802441 } & 7 & $\mathrm{q} 21.11$ & 86657787 & GRM3 & $\pi+C T$ & $51(27.4)$ & $23(30.2)$ & 0.643 & $1.15(0.64-2.06)$ \\
\hline & & & & & $\mathrm{CC}$ & $135(72.6)$ & $53(69.8)$ & & 1 \\
\hline \multirow[t]{2}{*}{ rs802466 } & 7 & q21.11 & 86698122 & GRM3 & $\mathrm{CC}+\mathrm{CT}$ & 35 (18.8) & $9(11.8)$ & 0.171 & $0.58(0.26-1.27)$ \\
\hline & & & & & $\pi$ & $151(81.2)$ & $67(88.2)$ & & 1 \\
\hline \multirow[t]{2}{*}{ rs12704286 } & 7 & q21.11 & 86745625 & GRM3 & $A A+A G$ & $60(33.3)$ & 27 (38.6) & 0.435 & $1.26(0.71-2.23)$ \\
\hline & & & & & GG & $120(66.7)$ & $43(61.4)$ & & 1 \\
\hline \multirow[t]{2}{*}{ rs17697415 } & 7 & q21.11 & 86772500 & GRM3 & $A A+A G$ & $22(11.8)$ & $12(15.8)$ & 0.387 & $1.40(0.65-2.99)$ \\
\hline & & & & & GG & $164(88.2)$ & $64(84.2)$ & & 1 \\
\hline \multirow[t]{2}{*}{ rs1873254 } & 6 & p21.31 & 34058712 & GRM4 & $A A+A G$ & $105(57.4)$ & $43(57.3)$ & 0.995 & $1.00(0.58-1.72)$ \\
\hline & & & & & GG & 78 (42.6) & $32(42.7)$ & & 1 \\
\hline \multirow[t]{2}{*}{ rs937039 } & 6 & p21.31 & 34075875 & GRM4 & $\mathrm{GG}+\mathrm{AG}$ & 44 (23.6) & $17(22.4)$ & 0.823 & $0.93(0.49-1.76)$ \\
\hline & & & & & AA & $142(76.4)$ & $59(77.6)$ & & 1 \\
\hline \multirow[t]{2}{*}{ rs1565361 } & 6 & p21.31 & 34089248 & GRM4 & $\mathrm{CC}+\mathrm{CT}$ & $84(45.2)$ & $33(43.4)$ & 0.797 & $0.93(0.54-1.60)$ \\
\hline & & & & & $\pi$ & $102(54.8)$ & $43(56.6)$ & & 1 \\
\hline \multirow[t]{2}{*}{ rs4106126 } & 11 & q14.2 & 88647181 & GRM5 & $\pi+C T$ & $43(23.1)$ & $18(23.7)$ & 0.922 & $1.03(0.55-1.94)$ \\
\hline & & & & & $\mathrm{CC}$ & $143(76.9)$ & $58(76.3)$ & & 1 \\
\hline \multirow[t]{2}{*}{ rs1391878 } & 11 & $\mathrm{q} 14.2$ & 88713212 & GRM5 & $\mathrm{CC}+\mathrm{CT}$ & $39(21.0)$ & $19(25.0)$ & 0.476 & $1.26(0.67-2.35)$ \\
\hline & & & & & $\pi$ & $147(79.0)$ & $57(75.0)$ & & 1 \\
\hline \multirow[t]{2}{*}{ rs12787863 } & 11 & $q 14.2$ & 88810547 & GRM5 & $A A+A G$ & 77 (41.4) & $33(43.4)$ & 0.763 & $1.09(0.63-1.86)$ \\
\hline & & & & & GG & 109 (58.6) & $43(56.6)$ & & 1 \\
\hline \multirow[t]{2}{*}{ rs7126679 } & 11 & $q 14.2$ & 89020677 & GRM5 & $A A+A G$ & $109(59.9)$ & $48(64.0)$ & 0.539 & $1.19(0.68-2.08)$ \\
\hline & & & & & GG & $73(40.1)$ & $27(36.0)$ & & 1 \\
\hline \multirow[t]{2}{*}{ rs2856354 } & 5 & q35.3 & 178978728 & GRM6 & $\mathrm{GG}+\mathrm{AG} A \mathrm{~A}$ & 81 (43.6) & $37(48.7)$ & 0.448 & $1.23(0.72-2.10)$ \\
\hline & & & & & & $105(56.4)$ & 39 (51.3) & & 1 \\
\hline
\end{tabular}


Table 2 Association of the genetic variants of glutamate receptor family genes in Taiwanese KD children according to the presence or absence of CAA (Continued)

\begin{tabular}{|c|c|c|c|c|c|c|c|c|c|}
\hline \multirow[t]{2}{*}{ rs10464073 } & 5 & q35.3 & 178982284 & GRM6 & $G G+A G$ & $81(43.6)$ & $37(48.7)$ & 0.448 & $1.23(0.72-2.10)$ \\
\hline & & & & & AA & $105(56.4)$ & $39(51.3)$ & & 1 \\
\hline \multirow[t]{2}{*}{ rs17078880 } & 5 & q35.3 & 178983436 & GRM6 & $\Pi+C T$ & $51(27.7)$ & $20(26.7)$ & 0.863 & $0.95(0.52-1.74)$ \\
\hline & & & & & $\mathrm{CC}$ & $133(72.3)$ & $55(73.3)$ & & 1 \\
\hline \multirow[t]{2}{*}{ rs2645341 } & 5 & q35.3 & 178984314 & GRM6 & $\mathrm{GG}+\mathrm{AG}$ & $53(28.5)$ & $19(25.0)$ & 0.565 & $0.84(0.45-1.54)$ \\
\hline & & & & & AA & $133(71.5)$ & $57(75.0)$ & & 1 \\
\hline \multirow[t]{2}{*}{ rs6764411 } & 3 & p26.1 & 7101864 & GRM7 & $C C+A C$ & $127(68.3)$ & $52(68.4)$ & 0.982 & $1.01(0.57-1.79)$ \\
\hline & & & & & AA & $59(31.7)$ & 24 (31.6) & & 1 \\
\hline \multirow[t]{2}{*}{ rs17697928 } & 3 & p26.1 & 7326084 & GRM7 & $A A+A G$ & $130(69.9)$ & $48(63.2)$ & 0.289 & $0.74(0.42-1.29)$ \\
\hline & & & & & GG & $56(30.1)$ & $28(36.8)$ & & 1 \\
\hline rs779741 & 3 & p26.1 & 7541915 & GRM7 & $C C+A C$ & $124(66.7)$ & $48(63.2)$ & 0.587 & $0.86(0.49-1.50)$ \\
\hline \multirow[t]{2}{*}{ rs1354405 } & 3 & p26.1 & 7690304 & GRM7 & $\mathrm{GG}+\mathrm{AG}$ & $103(55.4)$ & $38(50.0)$ & 0.428 & $0.81(0.47-1.38)$ \\
\hline & & & & & AA & $83(44.6)$ & $38(50.0)$ & & 1 \\
\hline \multirow[t]{2}{*}{ rs712723 } & 7 & q31.33 & 126439090 & GRM8 & $\mathrm{CC}+\mathrm{CT}$ & $115(61.8)$ & 59 (77.6) & 0.014 & $2.14(1.16-3.6)$ \\
\hline & & & & & & & & & 1 \\
\hline \multirow[t]{2}{*}{ rs17627206 } & 7 & q31.33 & 126793483 & GRM8 & $\Pi A A+A G$ & $71(38.2) 20(10.7)$ & $17(22.4) 8(10.5)$ & 0.957 & $0.98(0.41-2.32)$ \\
\hline & & & & & GG & 166 (89.3) & $68(89.5)$ & & 1 \\
\hline \multirow[t]{2}{*}{ rs11563505 } & 7 & q31.33 & 127059729 & GRM8 & $\Pi+C T$ & $46(24.7)$ & $19(25.0)$ & 0.964 & $1.01(0.55-1.88)$ \\
\hline & & & & & $\mathrm{CC}$ & $140(75.3)$ & $57(75.0)$ & & 1 \\
\hline
\end{tabular}

Physical position of individual SNPs was based on the NCBI Assembly database: GRCH38 version.

GRIK, glutamate receptor, ionotropic, kainate; GRIA, glutamate receptor, ionotropic, AMPA; GRM, glutamate receptor, metabotropic, SNP, single nucleotide polymorphism; $\mathrm{Cl}$, confidence interval.

$p$-values were obtained by chi-square test $(2 \times 2$ table).

Bold italic are significant at $p$ value $<0.05$.

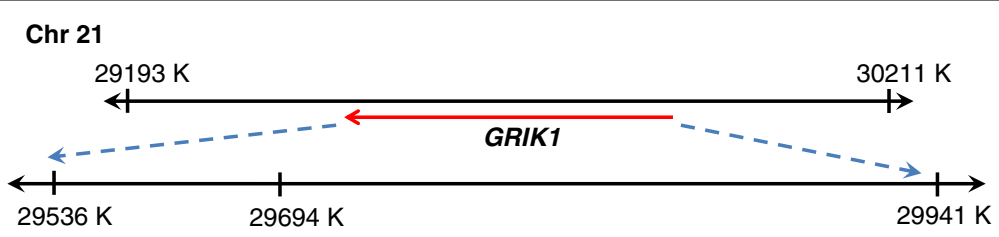

НHНHНHНHНH

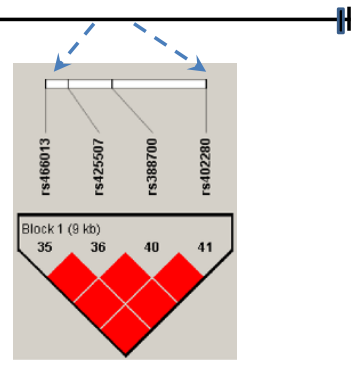

Figure 1 Analysis of single nucleotide polymorphisms (SNPs) and the linkage disequilibrium (LD) pattern of the GRIK1 gene. Genomic location of SNPs present on chromosome 21q21.3. Physical position of individual SNPs was based on the NCBI Assembly database: GRCh38 version. Linkage disequilibrium (LD) blocks in the GRIK1 gene, estimated by using HAPLOVIEW software. Pairwise D' values (\%) are indicated in squares; red indicates linkage disequilibrium $\left[D^{\prime}=1\right.$, logarithm of odds (LOD) $\left.\geq 2\right]$. 
Table 3 Association of GRIK1 genetic polymorphisms with CAA complications in Taiwanese KD children by multivariate regression analysis

\begin{tabular}{cccc}
\hline GRIK1 genetic polymorphisms & Odds ratio & 95\% CI & \multicolumn{1}{c}{$\boldsymbol{p}$ value } \\
\hline \multicolumn{4}{r}{ Full model (adjusted by fever duration and first IVIG used time) } \\
rs466013 & 2.12 & $1.22-3.65$ & $\mathbf{0 . 0 1 1}$ \\
rs425507 & 2.16 & $1.26-3.76$ & $\mathbf{0 . 0 0 9}$ \\
rs388700 & 2.16 & $1.26-3.76$ & $\mathbf{0 . 0 0 9}$ \\
rs402280 & 1.89 & $1.09-3.21$ & $\mathbf{0 . 0 2 8}$ \\
\hline
\end{tabular}

GRIK1, glutamate receptor, ionotropic, kainate 1 ; IVIG, Intravenous immunoglobulin; CAA, Coronary artery aneurysm; $\mathrm{Cl}$, confidence interval. Full model shows results from a logistic regression model including the indicated predictors, fever duration (days) and first IVIG used time (number of days after the first day of fever).

Bold italic are significant at $p$ value $<0.05$.

macrophages, lymphocytes, and chondrocytes [37,38]. These amino acids bind to iGluRs and mGluRs to regulate peripheral pain, release of cytokines and matrix metalloproteinases, and immune responses [39-41]. Our studies have firstly showed that glutamate receptors including NMDA [26] and $\mathrm{KA}$ receptors are involved in the CAA complications of KD regardless of the fever duration and first IVIG used time. $\mathrm{KD}$ is a multi-systemic disorder with a possible underlying pathology of immune-mediated vasculitis [1,42]. The vascular endothelium forms a functional barrier between the vessel wall and the bloodstream. Recent studies have shown that regulation of certain glutamate receptors may induce the inflammation of endothelial cells, thereby mediating pathogenesis of vascular diseases [43,44]. Although the current therapy for KD includes high doses of aspirin in conjunction with IVIG treatment [45], reports suggest that this regimen cannot efficiently prevent CAA development.

In this study, we showed that the glutamate receptor GRIK1 is significantly associated with KD with CAA complications in Taiwanese children with Han Chinese ethnic background. Genetic polymorphisms of the GRIK1 gene may play a role in KD pathogenesis and this molecule may serve as a therapeutic target for the KD treatment to prevent CAA development. Children with specific glutamate receptor genotypes related to $\mathrm{KD}$ should be careful assessed for CAA status at the time of diagnosis and monitored during the CAA development and related cardiovascular diseases. In addition to aspirin and IVIG therapy, the glutamate receptors may also serve as good targets for the design of novel KD therapeutics.

\section{Methods}

\section{Patients}

We performed a retrospective study. Individuals fulfilling the diagnostic criteria of KD $(n=262)$ were identified and enrolled into this study from the Department of Pediatrics at China Medical University Hospital in Taichung, Taiwan $[46,47]$. This study population has been previously used for SNP analysis and KD studies $[4,10,26,48,49]$. In this study, there were 164 males and 94 females with an average age at diagnosis $1.75 \pm$ 1.61 years. All the patients were diagnosed according to KD criteria [50]. All the patients underwent regular echocardiography examinations at the acute stage, 2 and 6 months after onset and once a year thereafter. CAA was identified when either the right or left coronary artery showed a dilated diameter of $3 \mathrm{~mm}$ in children younger than 5 years of age, or $4 \mathrm{~mm}$ in the older children [51]. According to the presence or absence of CAA, statistically significant differences between these 2 groups were found with respect to the fever duration and 1st IVIG used time (number of days after the first day of fever) $[26,48]$. Only Han Chinese individuals, who account for $98 \%$ of the Taiwanese residents, were considered for recruitment. This study was approved by the Human Studies Committee of China Medical University Hospital (CMUH REC No. DMR101-IRB1-313 (CR-1)).

\section{Consent}

The written informed consent was obtained from the patient's guardian/parent/next of kin for the publication of this report and any accompanying images.

\section{SNP genotyping}

Fifty-three single nucleotide polymorphisms (SNPs) of 16 genes within the glutamate receptor gene family including GRIK1, GRIK2, GRIK3, GRIK4, GRIK5, GRIA1, GRIA2, GRIA4, GRM1, GRM2, GRM3, GRM4, GRM5, GRM6, GRM7, and GRM8 were selected from the NCBI SNP database and HAPMAP website (Tables 2 and 3) [52]. Selection criteria for including SNPs in the analysis were a minimum allele frequency of $>0.05$ in the Han Chinese population and a Hardy-Weinberg equilibrium $(p>0.05)$. A summary of information on the SNPs in the glutamate receptor genes (location, position, rs number, and genotype) is presented in Table 1. Briefly, genomic DNA was extracted from peripheral blood leukocytes according to the standard protocols (Genomic DNA kit; Qiagen). SNPs were genotyped using a custom-designed VeraCode GoldenGate Genotyping Assay System (Illumina); genotyping was performed as outlined in http://www. illumina.com/.

Primers and probes were designed and created using Custom VeraCode GoldenGate Genotyping Assay System software. Genotype calls were automatically generated using GenCall software version 3.1.3. We assessed the 8 VeraCode runs individually for intra-plate inconsistencies (e.g., variation in fluorescence intensities). Genotype cluster plots generated by individual VeraCode and SAM assays were visually inspected for call quality. Plots that appeared to be "unusually" clustered (i.e., unlike the predicted spread in terms of software-generated HWE or 
distance between clusters $[\theta]$ ) were investigated further by selecting samples via direct Sanger sequencing for genotype confirmation. Samples were sequenced using Big Dye Terminator v3.1 (AB, Foster City, CA, USA) according to the manufacturer's guidelines, and sequenced with an $\mathrm{AB}$ 3730 genetic analyzer.

\section{Analysis of haplotype blocks}

Based on the HAPLOVIEW software, we used the Lewontin D' measure to estimate the intermarker coefficient of LD of patients [53]. The confidence interval (CI) of LD was estimated using a resampling procedure and then used to construct the haplotype blocks.

\section{Statistical analyses}

Data are expressed as means \pm standard deviation for continuous variables. Genotypes were obtained by direct count, followed by allele frequency calculations (Table 1 ). $X^{2}$ tests were performed to determine the differences in categorical variables, and the odds ratio and 95\% CI were calculated for the factors under consideration. Forward stepwise multivariate regression analyses were also performed to identify factors that contribute independently to CAA formation in KD. All statistical analyses were performed using SPSS (v12.0) for Windows.

\section{Additional files}

Additional file 1: Figure S1. Search results of single nucleotide polymorphism (SNP) of rs466013 of the GRIK1 gene used in this study (http://www.ncbi.nlm.nih.gov/projects/SNP/snp_ref.cgi?rs=466013). Above: Genomic location of rs466013 (pointed by red arrows; the NCBI Assembly database: GRCh37.p10 version). Down: Genomic location of rs466013 for 6 versions of the NCBI Assembly database (pointed by red arrows). Figure S2. Search results of single nucleotide polymorphisms (SNPs) of rs466013, rs425507, rs388700 and rs402280 of the GRIK1 gene used in this study (http://genome.ucsc.edu/cgi-bin/ hgTracks?db=hg18\&position=chr21\%3A30120300-30129700\&hgsid= 370279953_3haDCdtlwLEpPqkcmUFYdaAFYNhx). Above: Genomic location of the GRIK1 gene. Down: Genomic location of rs466013, rs425507, rs388700 and rs402280 (pointed by red arrows; the NCBI Assembly database: NCBI36/hg 18 version). Figure S3. GRIK1 mRNA expression levels in peripheral blood mononuclear cells according to the GRIK1 SNPs (rs388700 and rs402280) genotypes. The relative GRIK1 expression was detected by quantitative real-time RT-PCR, and expression from individuals with $\Pi+\mathrm{TA}$ genotypes was compared to that from individuals with AA genotype. The GRIK1 (NM_000830.3) primer sequences were 5'-gcggttagagatggatcaaca-3' (located at nucleotide 2559-2579 of the transcript (NM 000830.3) and 5'-tcatgaaagcccacatcttct-3' (located at nucleotide 2617-2637 of the transcript (NM_000830.3)). The relative expression levels were expressed as GRIK1 mRNA/ HPRT mRNA ratio. Figure S4. Venn diagram of 4 GWAS studies. Gene SNPs from 4 GWAS studies were used for searching for common gene SNPs by using Venny website (http://bioinfogp.cnb.csic.es/tools/venny/). Figure S5. Venn diagram of 4 GWAS studies. Gene SNPs from 4 GWAS studies were used for searching for common gene SNPs by using Venny website (http://bioinfogp. cnb.csic.es/tools/venny/). Figure S5. Venn diagram of 4 GWAS studies. Gene SNPs from 4 GWAS studies were used for searching for common gene SNPs by using Venny website (http://bioinfogp.cnb.csic.es/tools/venny/).
Additional file 2: Table S1. Characteristics of GWAS studies for KD susceptibility included in this meta-analysis. Table S2. Meta-analysis for previous reported GWAS studies for KD susceptibility.

\section{Competing interests}

The authors declare that they have no competing interests.

\section{Authors' contributions}

YJL, JSC, XL, and FJT conceived and designed the experiments. THL, CCL, $\mathrm{SMH}, \mathrm{CWL}$ and $\mathrm{HT}$ performed the experiments. WKC and $\mathrm{JHC}$ analyzed the data. JSC, XL, JYW, CHC, LCC, and TJH contributed reagents/materials/analysis tools. YJL and $\mathrm{XL}$ wrote the manuscript. All the authors have read and approved the final manuscript.

\section{Acknowledgments}

The authors wish to thank the Department of Pediatrics, China Medical University Hospital (CMUH) for administrative assistance and China Medical University (CMU) under the Aim for Top University Plan of the Ministry of Education, Taiwan. We also thank Drs. Kuan-Teh Jeang, Chia-Yen Chen, and Willy W. L. Hong for technical help and suggestions.

\section{Funding}

Financial support for this research was provided by CMU (CMU100-S-01), CMUH (DMR-103-039), and the Republic of China National Science Council (NSC100-2320-B-039-012-MY3).

\section{Author details}

'Department of Medical Research, China Medical University Hospital, Taichung, Taiwan. ${ }^{2}$ School of Chinese Medicine, China Medical University, Taichung, Taiwan. ${ }^{3}$ Department of Pediatrics, China Medical University Hospital, Taichung, Taiwan. ${ }^{4}$ National Institute of Allergy and Infectious Diseases, National Institutes of Health, Bethesda, Maryland, USA. ${ }^{5}$ Biostatistics Center, China Medical University, Taichung, Taiwan. ${ }^{6}$ Biostatistics Center and School of Public Health, Taipei Medical University, Taipei, Taiwan. ${ }^{7}$ Institute of Biomedical Sciences, Academia Sinica, Taipei, Taiwan. ${ }^{8}$ Department of Medical Laboratory Science and Biotechnology, China Medical University, Taichung, Taiwan. ${ }^{9}$ Division of Chinese Medicine, China Medical University Beigang Hospital, Yunlin County, Taiwan. ${ }^{10}$ Division of Chinese Medicine, Tainan Municipal An-Nan Hospital -China Medical University, Tainan, Taiwan.

${ }^{11}$ Asia University, Taichung, Taiwan.

Received: 7 February 2014 Accepted: 20 October 2014

Published: 19 November 2014

\section{References}

1. Burns JC, Glode MP: Kawasaki syndrome. Lancet 2004, 364:533-544.

2. Chang LY, Chang IS, Lu CY, Chiang BL, Lee CY, Chen PJ, Wang JT, Ho HN, Chen DS, Huang LM: Epidemiologic features of Kawasaki disease in Taiwan, 1996-2002. Pediatrics 2004, 114:e678-682.

3. Lin W, Liu HP, Chang JS, Lin YJ: Genetic variations within the PSORS1 region affect Kawasaki disease development and coronary artery aneurysm formation. Biomed 2013, 3:73-81.

4. Chang CJ, Kuo HC, Chang JS, Lee JK, Tsai FJ, Khor CC, Chang LC, Chen SP, Ko TM, Liu YM, Chen YJ, Hong YM, Jang GY, Hibberd ML, Kuijpers T, Burgner D, Levin M, Burns JC, Davila S, Chen YT, Chen CH, Wu JY, Lee YC: Replication and meta-analysis of GWAS identified susceptibility loci in Kawasaki disease confirm the importance of B lymphoid tyrosine kinase (BLK) in disease susceptibility. PLOS One 2013, 8:e72037.

5. Kim JJ, Park YM, Yoon D, Lee KY, Seob Song M, Doo Lee H, Kim KJ, Park IS, Nam HK, Weon Yun S, Ki Han M, Mi Hong Y, Young Jang G, Lee JK: Identification of KCNN2 as a susceptibility locus for coronary artery aneurysms in Kawasaki disease using genome-wide association analysis. J Hum Genet 2013, 58:521-525.

6. Yan Y, Ma Y, Liu Y, Hu H, Shen Y, Zhang S, Tao D, Wu Q, Peng Q, Yang Y: Combined analysis of genome-wide-linked susceptibility loci to Kawasaki disease in Han Chinese. Hum Genet 2013, 132:669-680.

7. Lin MT, Hsu CL, Chen PL, Yang WS, Wang JK, Fann CS, Wu MH: A genome-wide association analysis identifies novel susceptibility loci for coronary arterial lesions in patients with Kawasaki disease. Trans/ Res 2013, 161:513-515. 
8. Onouchi Y: Genetics of Kawasaki disease: what we know and don't know. Circ J 2012, 76:1581-1586.

9. Onouchi Y, Ozaki K, Burns JC, Shimizu C, Terai M, Hamada H, Honda T, Suzuki H, Suenaga T, Takeuchi T, Yoshikawa N, Suzuki Y, Yasukawa K, Ebata R, Higashi K, Saji T, Kemmotsu Y, Takatsuki S, Ouchi K, Kishi F, Yoshikawa T, Nagai T, Hamamoto K, Sato Y, Honda A, Kobayashi H, Sato J, Shibuta S, Miyawaki $M$, Oishi $K$, et al: A genome-wide association study identifies three new risk loci for Kawasaki disease. Nat Genet 2012, 44:517-521.

10. Lee YC, Kuo HC, Chang JS, Chang LY, Huang LM, Chen MR, Liang CD, Chi H, Huang FY, Lee ML, Huang YC, Hwang B, Chiu NC, Hwang KP, Lee PC, Chang LC, Liu YM, Chen YJ, Chen CH, Chen YT, Tsai FJ, Wu JY: Two new susceptibility loci for Kawasaki disease identified through genome-wide association analysis. Nat Genet 2012, 44:522-525.

11. Khor CC, Davila S, Breunis WB, Lee YC, Shimizu C, Wright VJ, Yeung RS, Tan DE, Sim KS, Wang JJ, Wong TY, Pang J, Mitchell P, Cimaz R, Dahdah N, Cheung YF, Huang GY, Yang W, Park IS, Lee JK, Wu JY, Levin M, Burns JC, Burgner D, Kuijpers TW, Hibberd ML: Genome-wide association study identifies FCGR2A as a susceptibility locus for Kawasaki disease. Nat Genet 2011, 43:1241-1246.

12. Kim JJ, Hong YM, Sohn S, Jang GY, Ha KS, Yun SW, Han MK, Lee KY, Song MS, Lee HD, Kim DS, Lee JE, Shin ES, Jang JH, Lee YS, Kim SY, Lee JY, Han BG, Wu JY, Kim KJ, Park YM, Seo EJ, Park IS, Lee JK: A genome-wide association analysis reveals $1 \mathrm{p} 31$ and 2p13.3 as susceptibility loci for Kawasaki disease. Hum Genet 2011, 129:487-495.

13. Burgner D, Davila S, Breunis WB, Ng SB, Li Y, Bonnard C, Ling L, Wright VJ, Thalamuthu A, Odam M, Shimizu C, Burns JC, Levin M, Kuijpers TW, Hibberd ML: A genome-wide association study identifies novel and functionally related susceptibility Loci for Kawasaki disease. PLOS Genet 2009, 5:e1000319.

14. Tsai FJ, Lee YC, Chang JS, Huang LM, Huang FY, Chiu NC, Chen MR, Chi H, Lee YJ, Chang LC, Liu YM, Wang HH, Chen CH, Chen YT, Wu JY: Identification of novel susceptibility Loci for kawasaki disease in a Han chinese population by a genome-wide association study. PLoS One 2011, 6:e16853.

15. Peng Q, Chen C, Zhang Y, He H, Wu Q, Liao J, Li B, Luo C, Hu X, Zheng Z, Yang Y: Single-nucleotide polymorphism rs2290692 in the 3'UTR of ITPKC associated with susceptibility to Kawasaki disease in a Han Chinese population. Pediatr Cardiol 2012, 33:1046-1053.

16. Debanne D, Daoudal G, Sourdet V, Russier M: Brain plasticity and ion channels. J Physiol Paris 2003, 97:403-414

17. Diguet E, Fernagut PO, Normand E, Centelles L, Mulle C, Tison F: Experimental basis for the putative role of GluR6/kainate glutamate receptor subunit in Huntington's disease natural history. Neurobiol Dis 2004, 15:667-675.

18. Meldrum B: Amino acids as dietary excitotoxins: a contribution to understanding neurodegenerative disorders. Brain Res Brain Res Rev 1993, 18:293-314.

19. Rogers SW, Andrews PI, Gahring LC, Whisenand T, Cauley K, Crain B, Hughes TE, Heinemann SF, McNamara JO: Autoantibodies to glutamate receptor GluR3 in Rasmussen's encephalitis. Science 1994, 265:648-651.

20. Bolton C, Paul C: Glutamate receptors in neuroinflammatory demyelinating disease. Mediators Inflamm 2006, 2006:93684.

21. Chen H: Possible Role of Platelet GluR1 Receptors in Comorbid Depression and Cardiovascular Disease. Cardiovasc Psychiatry Neurol 2009, 2009:424728.

22. Morrell CN, Sun H, Ikeda M, Beique JC, Swaim AM, Mason E, Martin TV, Thompson LE, Gozen O, Ampagoomian D, Sprengel R, Rothstein J, Faraday N Huganir R, Lowenstein CJ: Glutamate mediates platelet activation through the AMPA receptor. J Exp Med 2008, 205:575-584.

23. Lin SH, Maiese K: Group I metabotropic glutamate receptors prevent endothelial programmed cell death independent from MAP kinase p38 activation in rat. Neurosci Lett 2001, 298:207-211.

24. Chen $\mathrm{CH}$, Beard RS, Bearden SE: Homocysteine impairs endothelial wound healing by activating metabotropic glutamate receptor 5 . Microcirculation 2012, 19:285-295.

25. Chen Z, Du ZD, Liu JF, Lu DX, Li L, Guan YQ, Wan SG: Endothelial progenitor cell transplantation ameliorates elastin breakdown in a Kawasaki disease mouse model. Chin Med J (Engl) 2012, 125:2295-2301.

26. Lin YJ, Chang JS, Liu X, Hung CH, Lin TH, Huang SM, Jeang KT, Chen CY, Liao CC, Lin CW, Lai CH, Tien N, Lan YC, Ho MW, Chien WK, Chen JH, Huang YC, Tsang H, Wu JY, Chen CH, Chang LC, Tsai FJ: Association between GRIN3A Gene Polymorphism in Kawasaki Disease and Coronary Artery Aneurysms in Taiwanese Children. PLoS One 2013, 8:e81384

27. Burgner D, Curtis N: Kawasaki disease as a cause of encephalitis. Arch Dis Child 2011, 96:988-989

28. Sander T, Hildmann T, Kretz R, Furst R, Sailer U, Bauer G, Schmitz B, Beck-Mannagetta G, Wienker TF, Janz D: Allelic association of juvenile absence epilepsy with a GluR5 kainate receptor gene (GRIK1) polymorphism. Am J Med Genet 1997, 74:416-421.

29. Izzi C, Barbon A, Kretz R, Sander T, Barlati S: Sequencing of the GRIK1 gene in patients with juvenile absence epilepsy does not reveal mutations affecting receptor structure. Am J Med Genet 2002, 114:354-359.

30. Shibata H, Joo A, Fujii Y, Tani A, Makino C, Hirata N, Kikuta R, Ninomiya H, Tashiro N, Fukumaki Y: Association study of polymorphisms in the GluR5 kainate receptor gene (GRIK1) with schizophrenia. Psychiatr Genet 2001, 11:139-144.

31. Hirata Y, Zai CC, Souza RP, Lieberman JA, Meltzer HY, Kennedy JL: Association study of GRIK1 gene polymorphisms in schizophrenia: casecontrol and family-based studies. Hum Psychopharmacol 2012, 27:345-351.

32. Kranzler HR, Gelernter J, Anton RF, Arias AJ, Herman A, Zhao H, Burian L, Covault J: Association of markers in the $3^{\prime}$ region of the GluR5 kainate receptor subunit gene to alcohol dependence. Alcohol Clin Exp Res 2009, 33:925-930.

33. Kranzler HR, Covault J, Feinn R, Armeli S, Tennen H, Arias AJ, Gelernter J, Pond T, Oncken C, Kampman KM: Topiramate treatment for heavy drinkers: moderation by a GRIK1 polymorphism. Am J Psychiatry 2014, 171:445-452.

34. Kranzler HR, Armeli S, Feinn R, Tennen H, Gelernter J, Covault J: GRIK1 Genotype moderates topiramate's effects on daily drinking level, expectations of alcohol's positive effects and desire to drink. Int $J$ Neuropsychopharmacol 2014, 17:1549-1556.

35. Ray LA, Miranda R Jr, MacKillop J, McGeary J, Tidey JW, Rohsenow DJ, Gwaltney C, Swift RW, Monti PM: A preliminary pharmacogenetic investigation of adverse events from topiramate in heavy drinkers. Exp Clin Psychopharmacol 2009, 17:122-129.

36. Li S, Qian J, Yang Y, Zhao W, Dai J, Bei JX, Foo JN, McLaren PJ, Li Z, Yang J, Shen F, Liu L, Pan S, Wang Y, Li W, Zhai X, Zhou B, Shi L, Chen X, Chu M, Yan Y, Wang J, Cheng S, Shen J, Jia W, Liu J, Wen Z, Li A, Zhang Y, Zhang G, et al: GWAS identifies novel susceptibility loci on 6 p21.32 and 21q21.3 for hepatocellular carcinoma in chronic hepatitis B virus carriers. PLoS Genet 2012, 8:e1002791.

37. Lawand NB, McNearney T, Westlund KN: Amino acid release into the knee joint: key role in nociception and inflammation. Pain 2000, 86:69-74

38. Piepoli T, Mennuni L, Zerbi S, Lanza M, Rovati LC, Caselli G: Glutamate signaling in chondrocytes and the potential involvement of NMDA receptors in cell proliferation and inflammatory gene expression. Osteoarthritis Cartilage 2009, 17:1076-1083.

39. Flood S, Parri R, Williams A, Duance V, Mason D: Modulation of interleukin-6 and matrix metalloproteinase 2 expression in human fibroblast-like synoviocytes by functional ionotropic glutamate receptors. Arthritis Rheum 2007, 56:2523-2534.

40. Lindblad SS, Mydel P, Hellvard A, Jonsson IM, Bokarewa MI: The N-methyl$\mathrm{d}$-aspartic acid receptor antagonist memantine ameliorates and delays the development of arthritis by enhancing regulatory $T$ cells. Neurosignals 2012, 20:61-71.

41. Miller KE, Hoffman EM, Sutharshan M, Schechter R: Glutamate pharmacology and metabolism in peripheral primary afferents: physiological and pathophysiological mechanisms. Pharmacol Ther 2011 130:283-309.

42. Burns JC: Commentary: translation of Dr. Tomisaku Kawasaki's original report of fifty patients in 1967. Pediatr Infect Dis J 2002, 21:993-995.

43. Sharp CD, Houghton J, Elrod JW, Warren A, Jackson TH, Jawahar A, Nanda A, Minagar A, Alexander JS: N-methyl-D-aspartate receptor activation in human cerebral endothelium promotes intracellular oxidant stress. Am J Physiol Heart Circ Physiol 2005, 288:H1893-1899.

44. Yoshio T, Okamoto H, Hirohata S, Minota S: IgG anti-NR2 glutamate receptor autoantibodies from patients with systemic lupus erythematosus activate endothelial cells. Arthritis Rheum 2013, 65:457-463.

45. Weng KP, Ou SF, Lin CC, Hsieh KS: Recent advances in the treatment of Kawasaki disease. J Chin Med Assoc 2011, 74:481-484. 
46. Newburger JW, Takahashi M, Gerber MA, Gewitz MH, Tani LY, Burns JC, Shulman ST, Bolger AF, Ferrieri P, Baltimore RS, Wilson WR, Baddour LM, Levison ME, Pallasch TJ, Falace DA, Taubert KA: Diagnosis, treatment, and long-term management of Kawasaki disease: a statement for health professionals from the Committee on Rheumatic Fever, Endocarditis, and Kawasaki Disease, Council on Cardiovascular Disease in the Young, American Heart Association. Pediatrics 2004, 114:1708-1733.

47. Falcini F: Kawasaki disease. Curr Opin Rheumatol 2006, 18:33-38.

48. Lin YJ, Chang JS, Liu X, Lin TH, Huang SM, Liao CC, Lin CW, Chien WK, Chen JH, Wu JY, Chen CH, Chang LC, Tsang H, Jeang KT, Chen CY, Tsai FJ: Sorting nexin 24 genetic variation associates with coronary artery aneurysm severity in Kawasaki disease patients. Cell Biosci 2013, 3:44

49. Lin YJ, Lan YC, Lai CH, Lin TH, Huang SM, Liao CC, Lin CW, Hung CH, Tien N, Liu X, Chien WK, Chen JH, Tsai FJ: Association of Promoter Genetic Variants in Interleukin-10 and Kawasaki Disease With Coronary Artery Aneurysms. J Clin Lab Anal 2014, 28:461-464.

50. Kim S, Dedeoglu F: Update on pediatric vasculitis. Curr Opin Pediatr 2005, 17:695-702.

51. Matsubara T, Furukawa S, Yabuta K: Serum levels of tumor necrosis factor, interleukin 2 receptor, and interferon-gamma in Kawasaki disease involved coronary-artery lesions. Clin Immunol Immunopathol 1990, 56:29-36.

52. Sherry ST, Ward MH, Kholodov M, Baker J, Phan L, Smigielski EM, Sirotkin K: dbSNP: the NCBI database of genetic variation. Nucleic Acids Res 2001, 29:308-311.

53. Barrett JC, Fry B, Maller J, Daly MJ: Haploview: analysis and visualization of LD and haplotype maps. Bioinformatics 2005, 21:263-265.

doi:10.1186/2045-3701-4-67

Cite this article as: Lin et al:: Genetic variants of glutamate receptor gene family in Taiwanese Kawasaki disease children with coronary artery aneurysms. Cell \& Bioscience 2014 4:67.

\section{Submit your next manuscript to BioMed Central and take full advantage of:}

- Convenient online submission

- Thorough peer review

- No space constraints or color figure charges

- Immediate publication on acceptance

- Inclusion in PubMed, CAS, Scopus and Google Scholar

- Research which is freely available for redistribution 